\title{
Analysis of Mobile Telecommunication Networks' Coverage and Internet Capacity to Support mHealth Applications in Blantyre City: A Case of TNM and Airtel Networks
}

\author{
Alinafe Kaliwo*, Chomora Mikeka, Harry Gombachika, Samuel Kaunda, Chifundo Mlangeni \\ Department of Electrical Engineering, University of Malawi, The Polytechnic, Private Bag 303, Chichiri, Blantyre 3 Malawi
}

\author{
${ }^{*}$ Corresponding Author \\ Alinafe Kaliwo
}

\section{Article History}

Received: 10.10 .2019

Accepted: 18.10 .2019

Published: 02.11.2019

\begin{abstract}
Background: Different authors have argued about the importance of telehealth in Sub-Sahara Africa. Mobile health applications have become the most popular type of the telehealth services under exploration. The success in deploying these mHealth applications hinge mainly on the mobile network coverage and the Internet capacity. In this research, the coverage and capacity of two main mobile network providers were analyzed with respect to the location of health centres and the population in the focus areas. Base stations managed by Telekom Networks Malawi PLC and Airtel Malawi Limited were analyzed by collecting secondary data from Malawi Communications Regulatory Authority and primary data was collected through the conducting of Internet speed tests at a sample of five health centres. The download and upload speeds and network latency data sets were analyzed using one-sample t-test method to find the deviation between recommended data speeds for different types of medical data and the means from network sample data that collected from sample health centres. Additional data on population and location of health centres was collected from National Statistical Office, Blantyre District Health Office. Results: By drawing network coverage maps using ArcGIS, results show that there is adequate network coverage for $2 \mathrm{G}, 3 \mathrm{G}$ and $4 \mathrm{G}$. At significances of $p$-value $<0.05$, using the $95 \%$ confidence interval one sample t-test, and by observing the mean differences the analysis shows that both networks can handle remote sensing data, emails and transfer of bio-signals like electromyography, electrocardiogram and electroencephalogram at all five-sample health centres. Conclusion: The data analysis shows weakness in both download and upload speeds at all sample health centres in IP telephony and High Definition video conferencing data.
\end{abstract}

Keywords: mHealth, Malawi, TNM, Airtel, Blantyre, internet, telemedicine, healthcare.

\section{INTRODUCTION}

Broadband cellular networks are becoming the most common solution for mobile data access to sharing world-wide information. Tele-health, on the other hand, is reshaping the health sector in various ways in the African Sub-Saharan region which continues to face big challenges in providing quality healthcare to its people, particularly those who are poor and living in rural areas [11].

\section{Mobile Telecommunications and Health Services in Blantyre City}

Telecom Networks Malawi (TNM) and Airtel Malawi Limited (Airtel) are key players in the telecommunication industry in Malawi with TNM covering over $74 \%$ and Airtel covering over $80 \%$ of the population. This industry has an important bearing on Malawi's economic growth and a major impact on implementation of mHealth solutions, hence good network coverage is essential to each network service provider.

Maoulidi discusses various health care services in Blantyre that are provided by the Ministry of Health (MoH), the Ministry of Local Government (MoLG) and the private sector [9]. The largest provider of health services in Blantyre is the public sector. Many health care services are provided by Queen Elizabeth Central Hospital (QECH), which is a central hospital run by the government [10].

Copyright @ 2019: This is an open-access article distributed under the terms of the Creative Commons Attribution license which permits unrestricted use, distribution, and reproduction in any medium for non commercial use (NonCommercial, or CC-BY-NC) provided the original author and source are credited. 
Recently, the field of mHealth technology has shown potential in tackling most of the world's health problems in access to diagnosis and treatment services due to the coming in of latest developments in medical technology. On the other hand, smartphones are rapidly becoming available in many low resource settings and their small size and weight facilitate their easiness to use [4] hence the application of mHealth in low- and middle-income countries shows positive impacts [1] particularly in Blantyre. Some of the projects include specialist advice applications in remote areas [3], drugs supply and stock management mobile applications.

The researchers in the project presented in this paper analyzed the network coverage and Internet capacity of the existing mobile network base station infrastructure to determine if it can be used to support various forms of tele-medical and mobile healthcare applications and technologies. The analysis was done by studying the vital base stations infrastructure properties that affect Internet data speed, radius of coverage and network priority in Blantyre city. The analysis intends to provide adequate literature of the readiness and capacity of mobile networks in Blantyre city to transmit various forms of biomedical data using mHealth applications.

\section{Problem Statement}

Despite the improvements in network coverage in Blantyre, there has been no study to ascertain the availability of mobile network infrastructure and coverage and the capacity of mobile Internet in supporting telemedicine and mobile mHealth applications in Blantyre. Although telemedicine offers such great hope in developing countries in the aspects of health data transfer, there is only limited published evidence to support this need for better telemedical solutions. One of the areas that need published evidence is that of mobile network readiness and capacity of the Internet to handle mHealth applications' transactions. Therefore, this research aimed at analyzing the current network coverage to determine its capability to support telemedical and mobile healthcare applications in Blantyre city.

\section{Research Objectives}

The research aimed at analyzing the mobile telecommunication base station infrastructure for Airtel and TNM networks in Blantyre city. A base station is an equipment in a mobile telecommunication infrastructure set-up responsible for transmitting and receiving electromagnetic radio waves and, therefore, is integral to network coverage. This analysis firstly required data collection from the two main mobile service providers (TNM and Airtel) and also the regulatory body, Malawi Communications Regulatory Authority (MACRA). The data collected was on base station locations, network parameters, radius of network coverage of the base station in relation to population of the location and power parameters of the base station. This data was then analyzed using IBM Statistical Package for Social Sciences. The analysis portrayed the usage of each network Internet capacity based on generations (2G, 3G and $4 G$ ) for each network. Furthermore, coverage maps were also draw using geographical information system (ArcGIS) to illustrate the coverage of different network capacities for each network but also showing healthcare institutions locations in relation to the base stations. Finally, the results were implemented in a MySQL database.

\section{LITERATURE REVIEW}

This chapter presents the theoretical concepts leading to the understanding of the problem and also the proposed solution by looking at telemedicine and mHealth applications, biomedical and telehealth applications that are of a great importance in Malawi.

\section{Telemedicine and Mobile Health Applications}

Telemedicine and mobile health applications provide an exchange of health information and enable health care services to be administered across geographical, time and cultural barriers. It is stated that rural areas experience a lower health level than in urban hence telemedicine and mobile health applications are considered important tools for enhancing health service delivery particularly in rural areas [7].

However, it was noted that telemedicine is underused in healthcare sector in Malawi having a rough percentage of about less than $10 \%$ of all healthcare services. Through research, it was found out that as the deployment and usability of wireless infrastructure (base stations) in rural areas and urban increase, telemedicine applications could be utilized on a larger scale [2].

In the year 2000, there was an experimental field trial conducted on home tele-care system using cable television plants in order to curb the inconvenience that is caused by routine transportation of very ill and handicapped patients. It was conducted using cable-TV infrastructure that supports Electro-Cardiogram (ECG) and Blood pressure (BP) information with audio and video communications among patients and healthcare providers [14].

Interoperability of systems such as computers, networks and communication devices with other health system components is very critical and key for effective and efficient delivery for telemedicine or mobile health applications [12]. In Malawi, an experimental analysis was done on a performance of wireless long-medium range link in healthcare applications [6]. The researchers found out that the employment of wireless networking in healthcare applications could be limited by jitter, packet losses and delays. However, their experiment was conducted on pilot network where there was less traffic as such would vary if the same experiment was conducted on heavily and fully operational wireless network. 
Looking at some telehealth systems deployed elsewhere, in India, UK-based Loughborough University's engineers entered into a partnership with experts from India to develop a unique mobile phone health monitoring system to be deployed in both rural and urban slums of India in order to improve management of primary health care [17]. The system included a development of a patient database management system, interaction between doctor and patient, capture of medical data acquisition- such as ECG, images of heart \& lung, eye and scheduling management.

Among some, the project involved SMS interface for integrating SMS messages from the patients using Second Generation (2G) mobile systems (GSM/CDMA) into the information system. Secondly, Wireless Access Point (WAP) gateway for web access applications using Wireless Mark-up Language (WML) for integrating GPRS/3G/4G mobile devices of doctors and nurses with the web server.

Another important literature that set a baseline of this research was from a journal that was written in the year 2009, by United Nations Foundations and Vodafone Foundation on mHealth for Development: The Opportunity of Mobile Technology for Healthcare in Developing World [18]. Variety of approaches were explored to dealing with different healthcare challenges in developing countries through the acceleration of collecting and storing patients' data. It relayed some ways of meeting with health needs. These included educations and awareness by using short message service (SMS) alerts, remote data collection conducted via smartphones, personal digital assistant (PDA) or mobile phones instead of using paper-based surveys.

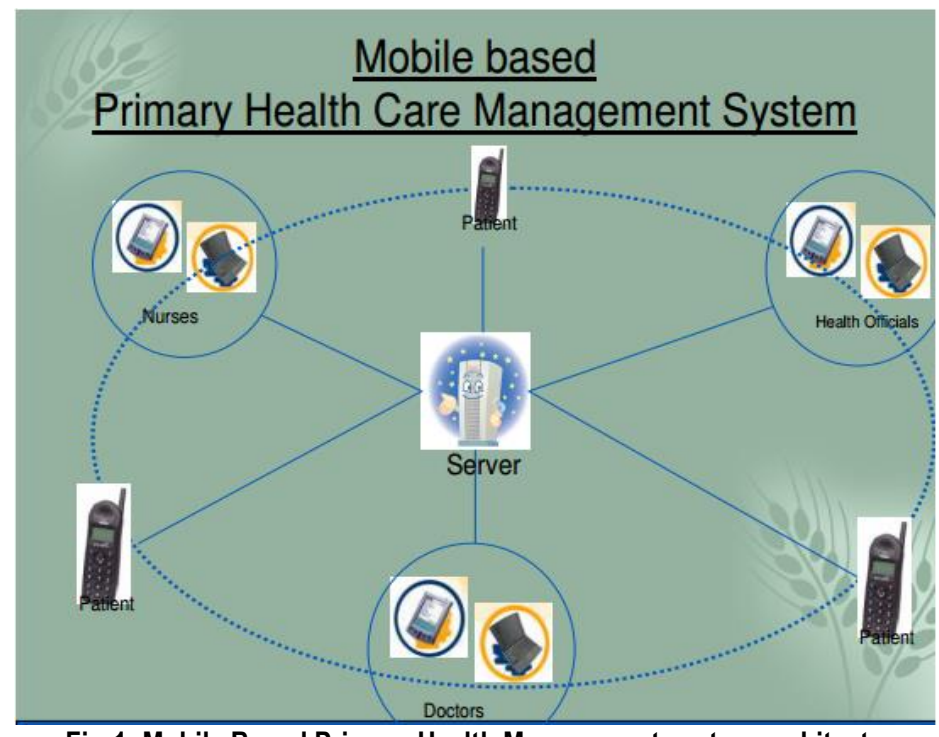

Fig-1: Mobile Based Primary Health Management system architecture

Another way involves remote control and treatment which provide a way of treating patients in outdoor setting. The applications used in this case include one or two-way communications to monitor health conditions, to maintain caregiver appointments or keep track of medicine regimen. Last but not least method was done through diagnosis and treatment support. This was aimed at helping patients get treatment and support in their respective villages (homes), averting the need for expensive healthcare visits.

In 2017, Saravannan and Dr. Sudhakar, wrote a journal on telemedicine technology using Internet communication [16]. This journal highlighted the major applications of telecommunications in health sector, the bio-medical services, the generations in mobile communication and their uses in telemedicine. It discusses the three application of healthcare treatment which include store and forward, remote patient monitoring and real-time interaction. It states that store and forward involves collecting medical data like X-Ray images and transmitting it to a doctor at convenient time. Remote patient monitoring means monitoring patients using technology like computer, mobile and medical instruments used for managing chronic diseases or specific and conditions like diabetes. Real time interactive services provide interactions between doctor or medical technician and patient. Services may include ophthalmology checks and physical examination [16].

\section{Generations in Mobile Telecommunications}

Mobile telemedicine systems are based on different types of wireless technologies and data speeds depending on their application field [13]. The rapid growth of wireless communication technologies increased demands in network efficiency and speed of communication [15] to allow various applications. Moving across the generations, in time, there are notable improvements and advancements of mobile networks and their properties. This paper focuses of $2 \mathrm{G}, 3 \mathrm{G}$ and $4 \mathrm{G}$ networks. 
Introduced in 1991, the Second Generation, 2G, technology became the first to use digital signal for voice transmission (GSM) with a speed up to 64kbps coupled with many data services for mobile on a bandwidth range of $30-200 \mathrm{kHz}$. Considering the challenges faced in packet transferring which leads to lower levels of efficiency in the system, a standardize, single global network protocol, Third Generation (3G), was made with an utmost aim of increasing the clarity of signal. It was noted that $3 G$ uses high band width $(100 \mathrm{MHz})$ transmission hence power utilization expanded to a considerable measure which prompts decrease the battery life really quick [15].

To overcome challenges faced by using $3 G$, the Fourth Generation (4G) technology was invented. This is the most recent redesign of innovation in versatile correspondence field it is ten times quicker than $3 G$. $4 G$ depends on an innovation called LTE (Long-Term Evolution) a complete IP based innovation for data transmission [15].

\section{Medical Data Transfer Needs in Telehealth and mHealth Applications}

Telehealth data can be shared using various ways, of which common ones are through voice and fax, bio signal transfer and remote sensing, electronic mail service, IP telephony and video conferencing. The table below shows some of the speeds recommended to transmit various forms of medical data.

Table-1: Types of Telemedicine Data in Healthcare and their Recommended Data Speeds [8, 19]

\begin{tabular}{|l|l|l|}
\hline Medical Data Transfer Mode & $\begin{array}{l}\text { Recommended } \\
\text { Data Speeds }\end{array}$ & Bandwidth \\
\hline $\begin{array}{l}\text { Voice and Fax communications between Doctor patients, } \\
\text { remote sensing data }\end{array}$ & $100 \mathrm{bps}$ to $16 \mathrm{kbps}$ & $30 \mathrm{kHz}$ \\
\hline $\begin{array}{l}\text { Medical texts, images transfer by Email, remote sensing } \\
\text { data from motion sensors and EEG (12 leads) }\end{array}$ & $16 \mathrm{kbps}$ to $64 \mathrm{kbps}$ & $\begin{array}{l}200 \mathrm{kHz} \text { (8 slots } \\
\text { each } 25 \mathrm{kHz})\end{array}$ \\
\hline Bio-signals like ECG (6 - 12 leads), EMG & $64 \mathrm{kbps}$ to $2 \mathrm{Mbps}$ & $5 \mathrm{MHz}$ to $25 \mathrm{MHz}$ \\
\hline Medical IP Telephony and Video conferencing & $2 \mathrm{Mbps}$ to $10 \mathrm{Mbps}$ & $5 \mathrm{MHz}$ to $25 \mathrm{MHz}$ \\
\hline Medical HD video conferencing & $10 \mathrm{Mbps}$ to $1 \mathrm{Gbps}$ & $5 \mathrm{MHz}$ to $20 \mathrm{MHz}$ \\
\hline
\end{tabular}

\section{RESULTS}

This chapter presents results of the study, the designs and implementations and the analysis.

\section{Network Base Station Parameters in Blantyre}

Data collected from the Network Service Providers (Airtel and TNM) on base stations, shows that there are some parameters which are constant. The table below shows such parameters:

Table-6: Base Station Parameters in Blantyre City

\begin{tabular}{|c|c|c|c|}
\hline \\
\hline & & TNM & Airtel \\
\hline \multicolumn{4}{|l|}{ Parameters } \\
\hline Power & & 80 Watts & 60 Watts \\
\hline Bandwidth & Given by MACRA & $200 \mathrm{KHz} /$ channel & 200KHz/channel \\
\hline Beamwidth & & $65 d$ & $65 d$ \\
\hline \multirow{2}{*}{ Configured Cell coverage } & Urban & $4 \mathrm{~km}$ & Dynamic \\
\hline & Rural & $10-15 \mathrm{kms}$ & Dynamic \\
\hline
\end{tabular}

\section{Network Coverage in Blantyre City}

The two figures (Fig.3 and Fig.4) below show the locations of base stations for both Network Service Providers, TNM and Airtel, based on network generations (2G-GSM, 3G-UMTS and 4G-LTE). 


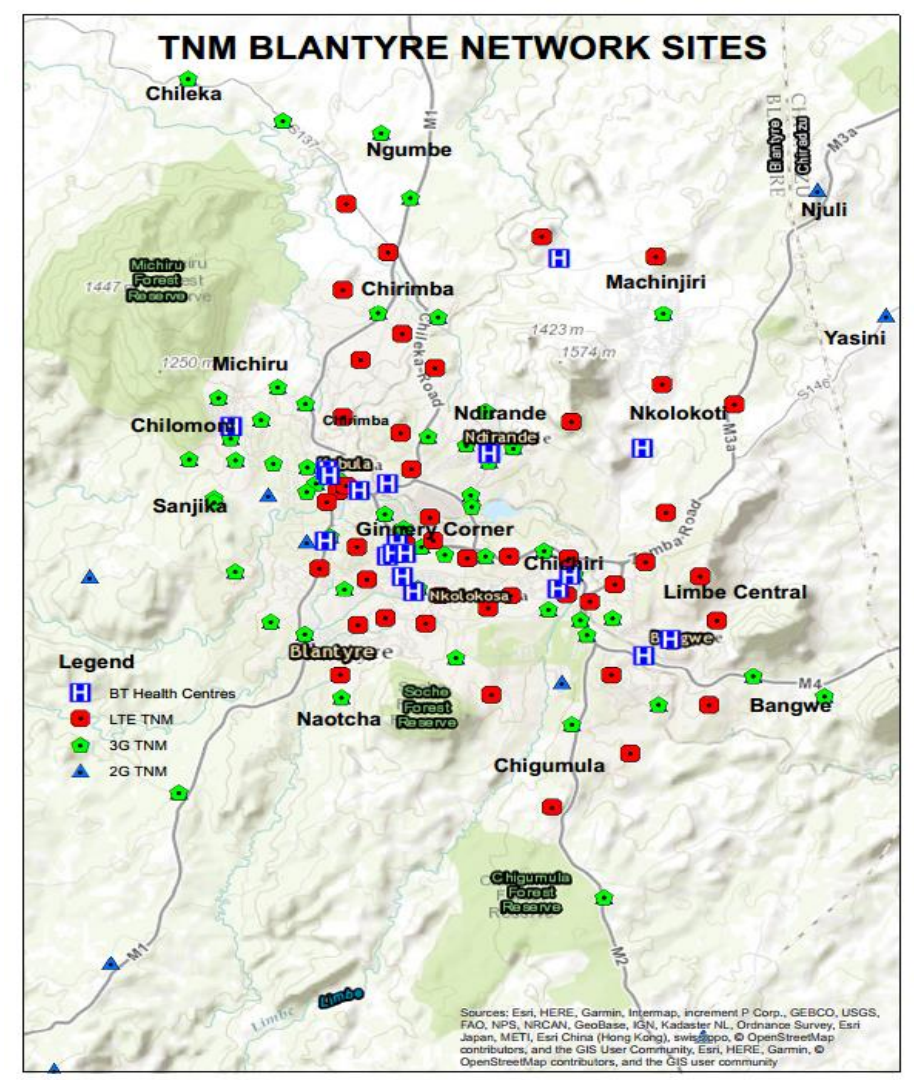

Fig-3: GIS Map Showing Health Centres and BTS Sites for 2G, 3G and 4G TNM Network in Blantyre

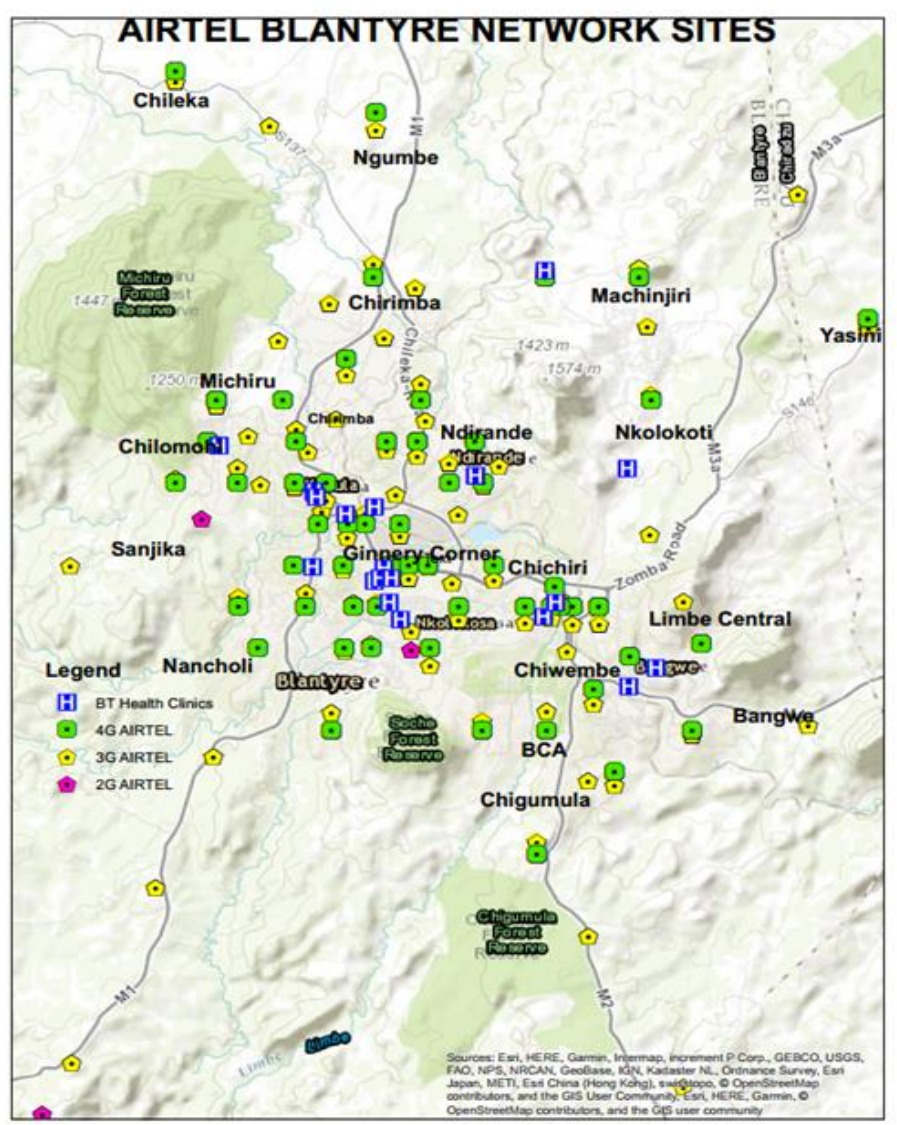

Fig-4: GIS Map Showing Health Centres and BTS Sites for 2G, 3G and 4G Airtel Network in Blantyre 
Using the data collected from MACRA, TNM and Airtel, coverage maps were produced using ArcGIS software as shown below in Fig.5 and Fig.6.
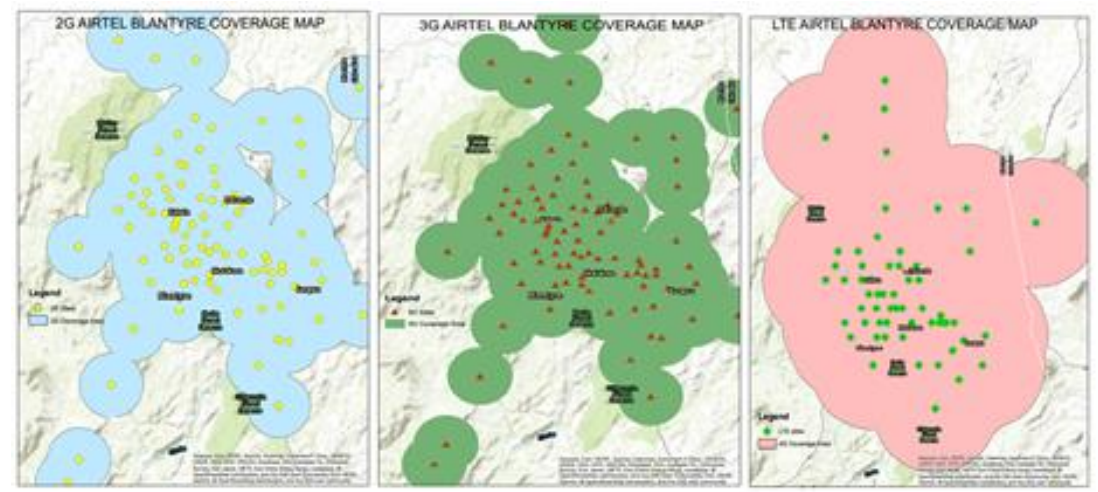

Fig-5: GIS Map Showing Coverages for 2G, 3G and 4G Airtel Networks Respectively in Blantyre

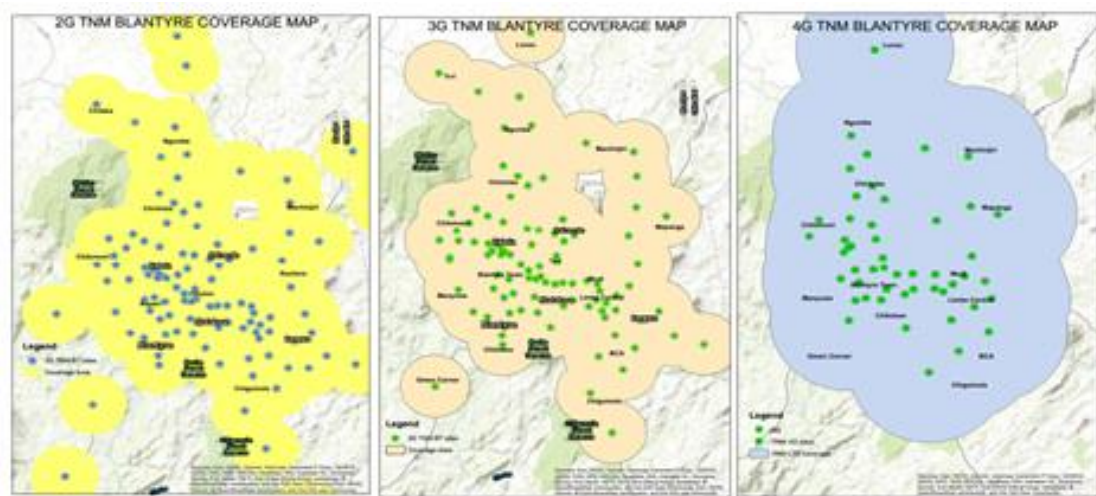

Fig-6: GIS Map Showing Coverages for 2G, 3G and 4G TNM Networks Respectively in Blantyre

From the speed tests that were conducted, the tables below show raw results of a one-sample T-test analysis of speeds for different Internet capacity based on generations $(2 G, 3 G$ or $4 G)$ taken at peak hours from the sample health centres. Speed is in Megabits per second units (Mbps)

Table-2: One-sample T-test results for 64kbps data types

\begin{tabular}{|c|c|c|c|c|c|c|c|}
\hline & & \multicolumn{6}{|c|}{ Test Value $=.064$} \\
\hline \multirow{2}{*}{\multicolumn{2}{|c|}{ HealthCentre }} & \multirow[b]{2}{*}{$t$} & \multirow[b]{2}{*}{ df } & \multirow[b]{2}{*}{ Sig. (2-tailed) } & \multirow{2}{*}{$\begin{array}{c}\text { Mean } \\
\text { Difference }\end{array}$} & \multicolumn{2}{|c|}{$\begin{array}{l}95 \% \text { Confidence Interval of the } \\
\text { Difference }\end{array}$} \\
\hline & & & & & & Lower & Upper \\
\hline \multirow[t]{2}{*}{ Bangwe } & Download Speed & 11.179 & 119 & .000 & 9.492244492 & 7.810861592 & 11.17362739 \\
\hline & Upload Speed & 8.601 & 119 & .000 & 5.694568450 & 4.383579787 & 7.005557113 \\
\hline \multirow[t]{2}{*}{ Chilomoni } & Download Speed & 11.521 & 116 & .000 & 7.113212855 & 5.890387082 & 8.336038627 \\
\hline & Upload Speed & 7.902 & 116 & .000 & 4.377570598 & 3.280319978 & 5.474821219 \\
\hline \multirow[t]{2}{*}{ Makhetha } & Download Speed & 9.416 & 116 & .000 & 12.41392744 & 9.802754877 & 15.02510001 \\
\hline & Upload Speed & 8.389 & 116 & .000 & 6.073461744 & 4.639572681 & 7.507350806 \\
\hline \multirow[t]{2}{*}{ Mlambe } & Download Speed & 11.545 & 92 & .000 & 10.65993677 & 8.826036368 & 12.49383718 \\
\hline & Upload Speed & 10.040 & 92 & .000 & 8.095639312 & 6.494243695 & 9.697034929 \\
\hline \multirow[t]{2}{*}{ Ndirande } & Download Speed & 7.638 & 89 & .000 & 3.894985867 & 2.881672920 & 4.908298813 \\
\hline & Upload Speed & 9.578 & 89 & .000 & 6.471722756 & 5.129100214 & 7.814345297 \\
\hline
\end{tabular}


Table-3: One-sample T-test results for 2 Mbps data types

\begin{tabular}{|c|c|c|c|c|c|c|c|}
\hline & & \multicolumn{6}{|c|}{ Test Value $=2$} \\
\hline \multirow{2}{*}{\multicolumn{2}{|c|}{ HealthCentre }} & \multirow[b]{2}{*}{$t$} & \multirow[b]{2}{*}{ df } & \multirow[b]{2}{*}{ Sig. (2-tailed) } & \multirow{2}{*}{$\begin{array}{c}\text { Mean } \\
\text { Difference }\end{array}$} & \multicolumn{2}{|c|}{$\begin{array}{l}95 \% \text { Confidence Interval of the } \\
\text { Difference }\end{array}$} \\
\hline & & & & & & Lower & Upper \\
\hline \multirow[t]{2}{*}{ Bangwe } & Download Speed & 8.899 & 119 & .000 & 7.556244492 & 5.874861592 & 9.237627391 \\
\hline & Upload Speed & 5.677 & 119 & .000 & 3.758568450 & 2.447579787 & 5.069557113 \\
\hline \multirow[t]{2}{*}{ Chilomoni } & Download Speed & 8.386 & 116 & .000 & 5.177212855 & 3.954387082 & 6.400038627 \\
\hline & Upload Speed & 4.407 & 116 & .000 & 2.441570598 & 1.344319978 & 3.538821219 \\
\hline \multirow[t]{2}{*}{ Makhetha } & Download Speed & 7.948 & 116 & .000 & 10.47792744 & 7.866754877 & 13.08910001 \\
\hline & Upload Speed & 5.715 & 116 & .000 & 4.137461744 & 2.703572681 & 5.571350806 \\
\hline \multirow[t]{2}{*}{ Mlambe } & Download Speed & 9.448 & 92 & .000 & 8.723936774 & 6.890036368 & 10.55783718 \\
\hline & Upload Speed & 7.639 & 92 & .000 & 6.159639312 & 4.558243695 & 7.761034929 \\
\hline \multirow[t]{2}{*}{ Ndirande } & Download Speed & 3.841 & 89 & .000 & 1.958985867 & .9456729205 & 2.972298813 \\
\hline & Upload Speed & 6.713 & 89 & .000 & 4.535722756 & 3.193100214 & 5.878345297 \\
\hline
\end{tabular}

Table-4: One-sample T-test results for 10Mbps data types

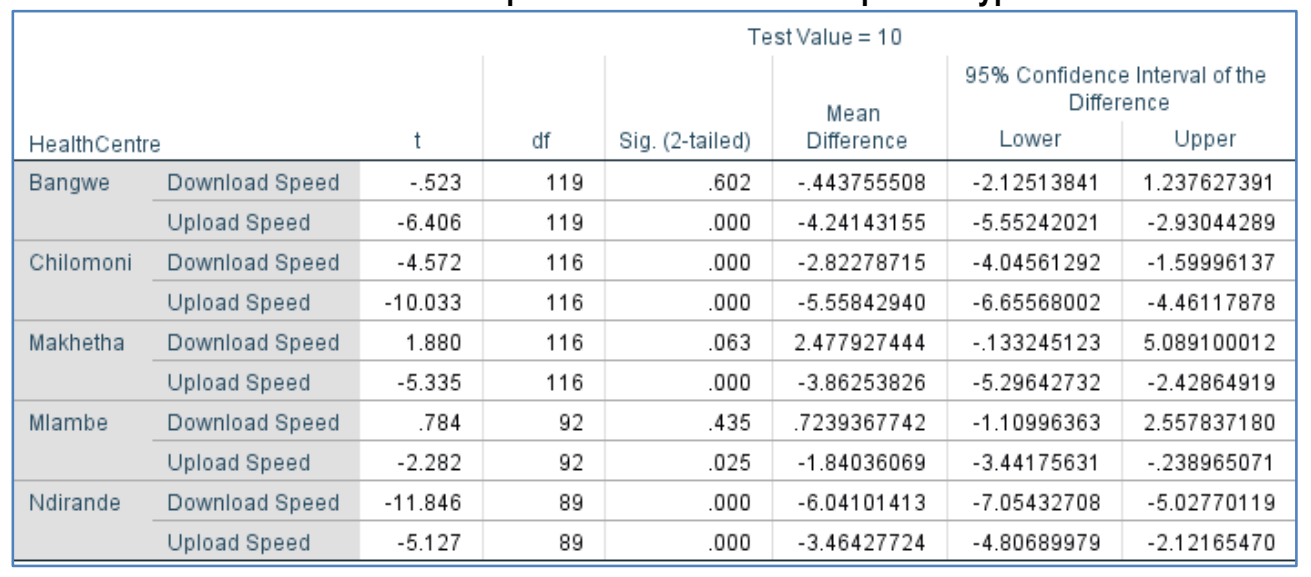

Table-5: One-sample T-test results for 25Mbps data types

\begin{tabular}{|c|c|c|c|c|c|c|c|}
\hline \multirow[b]{3}{*}{ HealthCentre } & & \multicolumn{6}{|c|}{ Test Value $=25$} \\
\hline & & \multirow[b]{2}{*}{$t$} & \multirow[b]{2}{*}{ df } & \multirow[b]{2}{*}{ Sig. (2-tailed) } & \multirow{2}{*}{$\begin{array}{c}\text { Mean } \\
\text { Difference }\end{array}$} & \multicolumn{2}{|c|}{$\begin{array}{l}95 \% \text { Confidence Interval of the } \\
\text { Difference }\end{array}$} \\
\hline & & & & & & Lower & Upper \\
\hline \multirow[t]{2}{*}{ Bangwe } & Download Speed & -18.188 & 119 & .000 & -15.4437555 & -17.1251384 & -13.7623726 \\
\hline & Upload Speed & -29.062 & 119 & .000 & -19.2414316 & -20.5524202 & -17.9304429 \\
\hline \multirow[t]{2}{*}{ Chilomoni } & Download Speed & -28.868 & 116 & .000 & -17.8227871 & -19.0456129 & -16.5999614 \\
\hline & Upload Speed & -37.110 & 116 & .000 & -20.5584294 & -21.6556800 & -19.4611788 \\
\hline \multirow[t]{2}{*}{ Makhetha } & Download Speed & -9.498 & 116 & .000 & -12.5220726 & -15.1332451 & -9.91089999 \\
\hline & Upload Speed & -26.055 & 116 & .000 & -18.8625383 & -20.2964273 & -17.4286492 \\
\hline \multirow[t]{2}{*}{ Mlambe } & Download Speed & -15.461 & 92 & .000 & -14.2760632 & -16.1099636 & -12.4421628 \\
\hline & Upload Speed & -20.886 & 92 & .000 & -16.8403607 & -18.4417563 & -15.2389651 \\
\hline \multirow[t]{2}{*}{ Ndirande } & Download Speed & -41.259 & 89 & .000 & -21.0410141 & -22.0543271 & -20.0277012 \\
\hline & Upload Speed & -27.326 & 89 & .000 & -18.4642772 & -19.8068998 & -17.1216547 \\
\hline
\end{tabular}

\section{Discussions}

Airtel and TNM configure their sites with 60 Watts and 80 Watts power sources respectively. These power ratings are uniform but the difference comes in the number of transceivers (TRXs) a site can have. On average, a site in town (urban area) has six TRXs and site in rural area has two TRXs active. Since the power sources are constant, 80 or 60 Watts, it follows that the more the TRXs per site the less power per TRX.

Power of a transceiver (TRX) has a bearing on the cell coverage. So, in rural areas, since the base stations are spaced, the power shared among the two TRX makes it possible for each cell to have a wider cell radius. This is not the case with urban areas because base stations are closely spaced i.e. at distances of two to four kilometres apart.

Using the speed tests results which depicted the download and upload speeds, it can be concluded that the two mobile 
networks have the Internet capacity to transmit the following telemedicine data transfer in real-time (interactive data transfer with minimal delay): remote sensing data, medical texts, images transfer by email, data from motion sensors and EEG (12 leads), Biosignals like ECG (6 - 12 leads) and EMG. The two networks have limited Internet capacity in transmitting medical IP telephony and video conferencing data i.e. Airtel's $4 \mathrm{G}$ would need longer data transmission time than TNM to transfer the Monograph data.

At 3 of the 5 sample health centres, latency levels are within the recommended levels of $100 \mathrm{~ms}$ except for Ndirande and Mlambe health centres. In some health centres like Bangwe and Makhetha, base stations were close to the centres (within 200 meters radius). Higher values of Internet speed were noted at such centres.

Another vital consideration is the effect of the population densities on the speed and latency. So, the cell capacities and compare the speeds for different distinct places were explored.

In order to calculate the cell coverage capacity based on Freeman (2004), Erlang B formula which calculates the probability of call blocking rate (Pr) was used.

$$
\operatorname{Pr}[\text { Blocking }]=\frac{\frac{A^{C}}{C !}}{\sum_{k=0}^{C} \frac{A^{k}}{k !}}
$$

where $C$ is the number of trunked channels offered by a trunked radio system and $A$ is the total offered traffic[5]. From the calculation, it is found out that call blocking rate is $2 \%$. From this, knowing the number of channels existing at each base station, the Erlang B Traffic table to deduce the traffic (Erlang) per channel was used. Assuming that everyone makes 2 calls on average per hour and the holding time is 3 minutes (180 seconds), using the offered traffic (permissible traffic) is found by the equation:

$$
\text { Offered Traffic, } A=\frac{C h}{T}=\frac{2 \times 3}{60}=0.1
$$

Then using the number of Erlangs and offered traffic, we can calculate the cell density.

$$
\text { Erlangs }=\left(\frac{2.276}{22.76}\right)=\frac{\text { people at one time }}{\text { channel }}=0.1
$$

Therefore, offered traffic is 0.1 .

For a Base station with 6 channels, like those mostly in townships,

$$
\text { cell capacity }=22.76 \times 6=137
$$

In rural areas, most base stations consist of 2 channels. For these the cell coverage capacity was calculated as follows:

$$
\text { cell capacity }=22.76 \times 2=46
$$

Ndirande health centre has the slowest Internet speeds mainly because the surrounding population that the base station supports is the highest of all the centres. Furthermore, the mobile speed testing application could not send packets using the $2 \mathrm{G}$ type of the network even after numerous pings. 
Table-7: One Sample Statistics for Internet speeds at sample health centres

\begin{tabular}{|llr|c|c|c|}
\hline \multirow{2}{*}{ HealthCentre } & N & Mean & Std. Deviation & $\begin{array}{c}\text { Std. Error } \\
\text { Mean }\end{array}$ \\
\hline Bangwe & Download Speed & 120 & 9.556244492 & 9.301867576 & .8491404497 \\
\cline { 2 - 7 } & Upload Speed & 120 & 5.758568450 & 7.252745906 & .6620820894 \\
\hline \multirow{2}{*}{ Chilomoni } & Download Speed & 117 & 7.177212855 & 6.678132597 & .6173935770 \\
\cline { 2 - 7 } & Upload Speed & 117 & 4.441570598 & 5.992337832 & .5539918285 \\
\hline \multirow{2}{*}{ Makhetha } & Download Speed & 117 & 12.47792744 & 14.26021354 & 1.318357209 \\
\cline { 2 - 7 } & Upload Speed & 117 & 6.137461744 & 7.830797733 & .7239575065 \\
\hline \multirow{2}{*}{ Mlambe } & Download Speed & 93 & 10.72393677 & 8.904696082 & .9233739694 \\
\cline { 2 - 7 } & Upload Speed & 93 & 8.159639312 & 7.775744655 & .8063071598 \\
\hline \multirow{2}{*}{ Ndirande } & Download Speed & 90 & 3.958985867 & 4.838064283 & .5099767534 \\
\cline { 2 - 7 } & Upload Speed & 90 & 6.535722756 & 6.410353474 & .6757105862 \\
\hline \hline
\end{tabular}

\section{CONCLUSIONS}

Telemedicine is growing vastly in the health circles of Malawi and the Sub-Saharan Africa thus re-shaping the healthcare service delivery industry. People are deploying mobile health applications to enable easy sharing of health data. The sharing of this health data depends on the availability of adequate Internet to transmit the data that is presented in various forms. It was in such context that this research was carried out to determine the capacity of the condition of the existing mobile telecom infrastructure (coverage and Internet capacity) can support the mobile health applications in Blantyre city.

From the findings, it can be concluded that the Blantyre has good coverage case of both TNM and Airtel for all three Internet capacities $3 G$ and $4 G$ in all habitable parts of the city. The $2 G$ Internet speeds are the slowest of all the network types hence most mHealth applications cannot work well on $2 G$ type of networks in Blantyre city.

From the speeds and transit time analysis, it can be concluded that peak hour speed levels decrease due to traffic so mobile health applications can perform poorly; data transfer time would be more than twice in peak hours than in normal hours.

In order to get real-time data for network service parameters, for example Internet speed, for different base stations in different locations, there is need to conduct an ongoing drive test exercise in Blantyre at different times. This involves driving along different locations in Blantyre city and running a speed test application on mobile phones to get speeds for different Internet capacities $(2 \mathrm{G}, 3 \mathrm{G}$ and $4 \mathrm{G})$ for those locations.

The research has only been conducted in Blantyre city. It is therefore recommended that similar studies be conducted in all the cities and then in each and every district of Malawi.

\section{MethOdS}

This chapter presents the research methods employed, techniques used and procedures followed in this study in order to achieve the above goal and its associated objectives, the following procedure was used.

Firstly, secondary data was collected from MACRA, Airtel and TNM on base stations locations, radius of coverage and Internet capacity parameters used for all the base stations found in both rural and urban areas of the city of Blantyre. Furthermore, population data of all areas in Blantyre was be collected from National Statistical Office (NSO) in Zomba.

Data on all public hospitals and health centres located in Blantyre city was collected from the office of the District Health Officer (DHO) of Blantyre city. Multi-stage random sampling was then employed to collect the primary data. In this case, the population of base stations was divided into clusters according to geographic areas. Five the following sample health centres were chosen from the clusters to represent the number of health centres in Blantyre: Ndirande, Bangwe, Chilomoni, Mlambe and Makhetha.

Speed tests were conducted indoors and outdoors at the facilities of the aforementioned health centres to get the primary data using a mobile based application called Ookla Speed Test on both Airtel and TNM networks.

Once data was collected, it was analyzed using IBM SPSS Statistics. Data was analysed using one sample T-test on network parameters; Internet speed (upload and download) and network latency. Base station radius of coverage and cell density was also analysed using secondary data that was collected from MACRA, NSO, TNM and Airtel. 
Geographical Information Systems Software - ArcGIS version 10.2 was used to produce maps for collected data. Maps were drawn showing base stations in Blantyre city, their radii of coverage, their Internet capacity and healthcare institutions in those sampled locations.

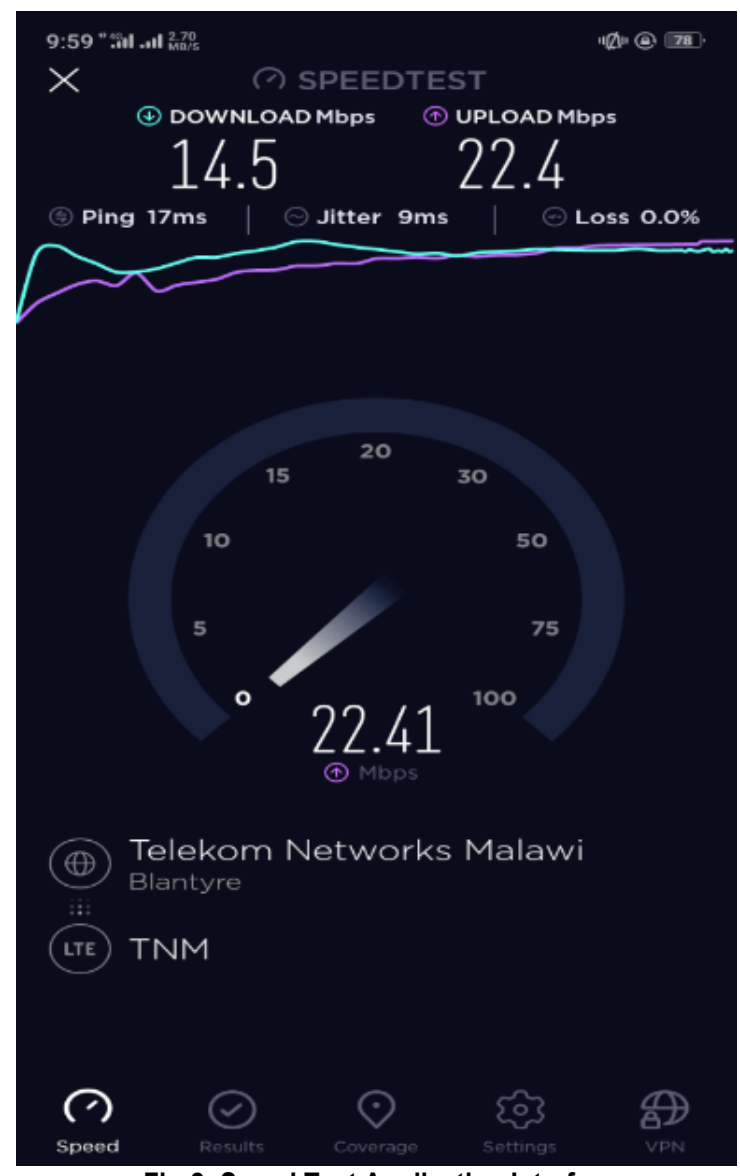

Fig-2: Speed Test Application Interface

\begin{tabular}{lll}
\multicolumn{2}{l}{ List of Abbreviation } & \\
DHO & - & District Health Officer \\
ECG & - & Electro-Cardiogram \\
EMG & - & Electromyography \\
GIS & - & Geographical Information Systems \\
MACRA & - & Malawi Communications Regulatory Authority \\
NSO & - & National Statistical Office \\
TNM & - & Telekom Networks Malawi PLC \\
WHO & - & World Health Organization
\end{tabular}

\section{Declarations}

\section{Ethics approval and consent to participate}

Not applicable

\section{Consent for publication}

Not applicable

\section{Availability of data and material}

The datasets generated during and/or analysed during the current study are available from the corresponding author on reasonable request.

\section{Competing interests}

The authors declare that they have no competing interests. 


\section{Funding}

The research that led to this publication was funded by the Department of Electrical Engineering at the Polytechnic, a constituent college of the University of Malawi. It should be noted, at this point, that the research was carried out as one of the activities for the award of the Master of Philosophy in Telecommunications Engineering being undertaken by the corresponding author.

\section{Authors' contributions:}

AK contributed in the conception and design of the work; the acquisition, analysis, interpretation of the speed test data. $\mathrm{CM}^{2}$ and HG have drafted the work, offered supervision and substantively revised it together with AK for the readiness for publication.

SK and $\mathrm{CM}^{1}$ developed the background of the research, collected secondary data from Airtel, TNM, MACRA and NSO and produced network coverage maps using ArcGIS.

\section{ACKNOWLEDGEMENTS}

The authors would like to thank the Department of Electrical Engineering and the entire Administration at the Polytechnic, a constituent college of the University of Malawi, for the academic and financial support towards tuition and research needs. Without their acceptance to fund the activities in the study, it would not have been possible to undertake this well-deserved endeavour

\section{REFERENCES}

1. Beratarrechea, A., Lee, A. G., Willner, J. M., Jahangir, E., Ciapponi, A., \& Rubinstein, A. (2014). The impact of mobile health interventions on chronic disease outcomes in developing countries: a systematic review. Telemedicine and e-Health, 20(1), 7582.

2. Breslauer, D. N., Maamari, R. N., Switz, N. A., Lam, W. A., \& Fletcher, D. A. (2009). Mobile phone based clinical microscopy for global health applications. PloS one, 4(7), e6320.

3. Chihanga, S., Tatarsky, A., Mosweunyane, T., Motlaleng, M., Bewlay, L., Digovich, K., ... \& Akrem, A. (2012). Toward malaria elimination in Botswana: a pilot study to improve malaria diagnosis and surveillance using mobile technology. Malaria journal, 11(1), P96.

4. Dunsmuir, D. T., Payne, B. A., Cloete, G., Petersen, C. L., Görges, M., Lim, J., ... \& Ansermino, J. M. (2014). Development of mHealth applications for pre-eclampsia triage. IEEE journal of biomedical and health informatics, 18(6), 1857-1864.

5. Freeman, R.: Telecommunication System Engineering. Wiley.

6. Gombachika, H. S., Chadza, T. A., Mkoloma, M., Mafuta, M., \& Bakolo, R. (2009). Experimental Performance Analysis of Wireless Links for Healthcare Applications. Malawi Journal of Science and Technology, 9(1), 1-4.

7. Jennett, P. A., Gagnon, M. P., \& Brandstadt, H. K. (2005). Preparing for success: readiness models for rural telehealth. Journal of postgraduate medicine, 51(4), 279.

8. Keikhosrokiani, P., Zakaria, N., Mustaffa, N., Wan, T. C., Sarwar, M. I., \& Azimi, K. (2015). Wireless networks in mobile healthcare. In Mobile Health (pp. 687-726). Springer, Cham.

9. Maoulidi, M. (2013). Health Needs Assessment for Blantyre City, Malawi. https://doi.org/10.7916/D8NS0SPB.

10. Metaferia, A.M., Muula, A.S. (2009). Stillbirths and hospital early neonatal deaths at Queen Elizabeth Central Hospital, BlantyreMalawi. International Archives of Medicine, 2(1) 25.

11. Murugesan, S. (2013). Mobile Apps in Africa. IT Professional, 15(5), 8-11

12. Ong, B. (2015). National Telemedicine Guidelines for Singapore.

13. Rahnema, M.: Overview of the GSM system and protocol architecture. IEEE Communications Magazine, 31(4), 92-100.

14. Lee, R. G., Chen, H. S., Lin, C. C., Chang, K. C., \& Chen, J. H. (2000). Home telecare system using cable television plants-an experimental field trial. IEEE Transactions on Information Technology in Biomedicine, 4(1), 37-44.

15. Sai Nitesh, G., Kakkar, A. (2016). Generations of Mobile Communication. Presented at the March 1.

16. Saravanan, S., Sudhakar, P. (2017). Telemedicine Technology Using Internet Communication.

17. Sharma, R.K. (2011). International Journal of Nursing Education, 3(1), 96.

18. UN: mHealth for Development: The Opportunity of Mobile Technology for Healthcare in the Developing World - World, https://reliefweb.int/report/world/mhealth-development-opportunity-mobile-technology-healthcare-developing-world.

19. Varshney, U. (2006). Using wireless technologies in healthcare. International Journal of Mobile Communications, 4(3), 354-368. 